\title{
Research Paper: Ventral Tegmental Area Microinjected- SKF38393 Increases Regular Chow Intake in 18 Hours Food-Deprived Rats
}

\author{
Farzaneh Saebi Rad $^{1,2}$ (D), Abbas Haghparast ${ }^{2}$ (D), Afsaneh Eliassi ${ }^{12^{*}}$ (D) \\ 1. Neurophysiology Research Center, Shahid Beheshti University of Medical Sciences, Tehran, Iran \\ 2. Department of Physiology, School of Medical, Shahid Beheshti University of Medical Sciences, Tehran, Iran
}

\begin{tabular}{|c|c|}
\hline $\begin{array}{l}\text { Use your device to scan } \\
\text { and read the article online }\end{array}$ & Itfat On Sahi Rad F Haghnarast A \& Fliassi A Ventral Teomental A \\
\hline 口ifing & $\begin{array}{l}\text { Chow Intake in } 18 \text { Hours Food-Deprived Rats. Basic and Clinical Neuroscience, 11(6), 773-780. http://dx.doi.org/10.32598/ } \\
\text { bcn.11.6.2226.1 }\end{array}$ \\
\hline a & 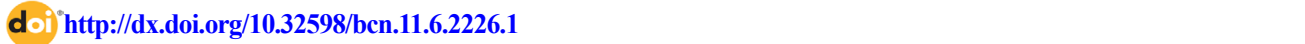 \\
\hline
\end{tabular}

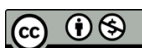

Article info:

Received: 24 Nov 2019

First Revision: 10 Dec 2019

Accepted: 26 Jan 2020

Available Online: 01 Nov 2020

Keywords:

Ventral Tegmental Area, Food intake, SKF38393, Eating

\section{A B S T RA C T}

Introduction: Ventral Tegmental Area (VTA) dopamine neurons play an important role in reward mechanisms of food intake, and VTA dopamine receptors exist on the terminal of glutamatergic and GABAergic neurons and regulate Gamma-Aminobutyric Acid (GABA) and glutamate release. To our knowledge, no evidence indicates any role for VTA D1 dopamine receptors in regular chow intake.

Methods: In this paper, different dose of SKF38393, a D1 receptor agonist, was microinjected in VTA of 18-h food deprived-conscious rats and food intake was measured.

Results: Our results revealed that VTAmicroinjected SKF383993 increased regular chow intake in a dose-dependent manner. The SKF3833 stimulatory effect persisted over $2 \mathrm{~h}$ post-injection. The results showed that the SKF38393, at doses less than $5 \mu \mathrm{g}$, did not affect locomotor activities.

Conclusion: VTA D1-like and/or serotonergic receptors may be involved in regulatory pathways. the current study suggests that VTA D1-like and/or serotonergic receptors not only affects food reward but is also involved in regulatory mechanisms of regular feeding.

\section{* Corresponding Author:}




\section{Highlights}

- The ventral tegmental area participates in the control of regular feeding.

- Microinjection of SKF38393 in the ventral tegmental area increases regular food intake.

- Ventral tegmental area D1-like and or serotonergic receptors may be involved in regulatory pathways.

\section{Plain Language Summary}

The Ventral Tegmental Area (VTA) has an essential role in food reward. For the first time, we showed that SKF38393 (a D1-like dopamine or serotonergic receptors agonist) increases regular food intake in a dose-dependent manner. Also, it does not affect locomotor activities. Our results suggest that VTA dopaminergic or serotonergic pathways may be involved in the homeostatic regulation of food intake. Based on the present findings, it is essential to understand the VTA mechanisms involved in regular food intake and its possible use in treating eating disorders.

\section{Introduction}

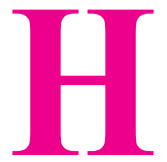

omeostatic and non-homeostatic controls are two separate categories to regulate feeding behavior. Homeostatic mechanisms affect food intake in response to metabolic needs and energy deficit, whereas non-homeostatic mechanisms regulate food intake based on hedonic and learned experiences. For example, the hypothalamus acts as a metabolic center (Gao \& Horvath, 2007), while the Ventral Tegmental Area (VTA) has a crucial role in food reward. Some reports have found that dopamine has a major role in reward-related learning and motivation (Wise, 2004). Natural stimuli (e.g. food, water) and drugs of abuse mediate their rewarding effects via the mesocorticolimbic dopamine system (Wise, 1978). In this regard, it has been suggested that the rewarding and motivational properties of food (Stricker \& Zigmond, 1984; Wang et al., 2001) are mediated by dopaminergic projections from VTA to the Nucleus Accumbens (NAc) (Wise, 2006), and during palatable food consumption, extracellular dopamine levels increase in the NAc (Datla, Ahier, Young, Gray, \& Joseph, 2002). Furthermore, depleted VTA dopamine neurons affect a wide range of behavior, including motivation (Papp \& Bal, 1986), memory (Wisman, Sahin, Maingay, Leanza, \& Kirik, 2008), drug self-administration (Corrigall, Franklin, Coen, \& Clarke, 1992), and perseveration (Pioli et al., 2008), but no data suggest that the depleted mesolimbic dopamine neurons influence feeding. However, it is difficult to interpret negative data in depleted dopamine neurons because even a small residual of dopamine may be sufficient to initiate feeding-related signals. Several experiments suggest that mesolimbic dopamine neurons participate in regulatory mechanisms of food rewards and have a limited role in free-feeding (Ljungberg, Apicella, \& Schultz, 1992; Mirenowicz \& Schultz, 1994) and standard food.

It should be mentioned that besides NAc, the central nucleus of the amygdala (Mogenson \& $\mathrm{Wu}, 1982$ ), prefrontal cortex (Berger, Thierry, Tassin, \& Moyne, 1976), and hippocampus (Scatton, Simon, Le Moal, \& Bischoff, 1980) are the major brain targets of VTA dopaminergic projections. In addition to DA neurons, glutamatergic and GABAergic neurons exist in the VTA and form local and long-range connections (Morales \& Root, 2014; Root et al., 2014). Dopamine D1 receptors present on the terminal of these neurons and regulate both glutamate and GABA release (Kalivas \& Duffy, 1995; Klitenick, DeWitte, \& Kalivas, 1992). Furthermore, GABA-containing terminals (Kalivas, 1993) and glutaminergic inputs synapse onto the VTA dopamine neurons (Smith, Charara, \& Parent, 1996). To our knowledge, no evidence proves that VTAD1 dopamine receptors may affect regular chow intake. We, therefore, hypothesized that VTA D1 receptors may modulate standard food intake. To accomplish this purpose, we administered the SKF38393 as a D1 agonist into the VTA and considered the effect of SKF38393 on food intake of food-deprived rats during an 18 -h period.

\section{Methods}

\subsection{Ethical consideration}

All animal experiments were authorized by the Research and Ethics Committee of Shahid Beheshti University of Medical Sciences (IR.SBMU.MSP.REC.1397.155). 


\subsection{Study animals}

Adult male Wistar rats (220-250 g, Neuroscience Research Center, Tehran, Iran) were housed in opaque polypropylene cages and maintained under a 12:12 h dark/light cycle at $22^{\circ} \mathrm{C}-24^{\circ} \mathrm{C}$. The animals were fed laboratory standard chow and water ad libitum. Before experiments, the rats were adapted to an $18 \mathrm{~h}$ deprivation of food with water freely available. After the VTA microinjections of SKF38393 or saline, the rats were individually housed with free access to food and water. All food intake measurements were done from Saturday to Wednesday at 9:00 AM and 12 PM.

\subsection{Drugs}

Ketamine from Rotex (Levallois-Perret, France), xylazine from Alfasan (Woerden, The Netherlands), and SKF38393 from Sigma (St Louis, MO, USA) were purchased.

\subsection{Surgery}

Intraperitoneal injections of ketamine $(70 \mathrm{mg} / \mathrm{kg}$ ) and xylazine $(10 \mathrm{mgkg})$ were used to anesthetize the animals. After anesthetizing, 23-gauge stainless steel cannula were implanted into the right VTA using the stereotaxic atlas of Paxinos and Watson (Paxinos \& Watson, 2006): lateral: 1 $\mathrm{mm}$ from midline; dorsoventral: $8 \mathrm{~mm}$ from skull surface; anteroposterior: $4.8 \mathrm{~mm}$ from the bregma. The injector was extended $1 \mathrm{~mm}$ beyond the end of the guide cannula. After a 7-day recovery period, SKF38393 or saline were injected over $30 \mathrm{~s}$ via a microsyringe pump (Stoelting, Lane Dale, IL, USA). All injections were done in a volume of $0.3 \mu \mathrm{L}$ using a $0.5-\mu$ L Hamilton.

\subsection{Histology}

After removing and fixing the brains in formalin, $100-\mu \mathrm{m}$ thick sections were prepared and the injection and cannula placement was examined with light microscopy. The data from animals in which the cannula placements were confirmed are shown in Figure 1.

\subsection{Food and activity measurement}

Food intake was measured by a Sartorius, TE3135 (Gottingen, Germany), with $\mathrm{d}=0.001 \mathrm{mg}$ accuracy. On the test day, the rats were moved to the laboratory at least $1 \mathrm{~h}$ before the experiments.

Immediately after the SKF38393 or saline injection, each rat was placed in an individual cage containing pre-measured amounts of regular food pellets. The rats were removed from the first test cage after 1 hour and each subsequent hour placed in new test cages over a $3 \mathrm{~h}$ period. After the rats were removed, the amount of food and crumbs in each cage was measured to calculate the quantity consumed by the rat located in that cage. Standard activity chambers interfaced with a Digiscan Animal were used to measure animal locomotor activity. The mean velocity $(\mathrm{cm} / \mathrm{s})$ was expressed as the unit of activity measurement.

\subsection{Treatments}

After a recovery period, SKF38393 $(0.75,1.25,2.5$, and 5 $\mu \mathrm{g})$, D1 receptor agonist, and saline were injected into the VTA. To minimize the number of animals used, each rat was used 3 times and the tests with drug or saline were conducted every $72 \mathrm{~h}$. During the resting period, the animals received sham injections instead of test drugs. No data were collected during this time.

\subsection{Statistical analysis}

Repeated measures Analysis of Variance (ANOVA) was used to check the differences between groups in the feeding study. One-way ANOVA was used to test food intake in the first hour, and repeated measurement 2-way ANOVA for the analysis of food intake during the next 3 hours followed by Tukey's HSD test. The differences between the SKF38393treated and saline groups were evaluated with the Student unpaired $t$ test analysis. We consider $(\mathrm{P}<0.05)$ statistically significant. Results are reported as Mean \pm SEM.

\section{Results}

\subsection{Influence of SKF38393 on food intake}

Intra-ventral tegmental area injections of SKF38393 $(0.75,1.25,2.5$, and $5 \mu \mathrm{g})$ increased regular food intake in a dose-dependent manner $\left(\mathrm{F}_{4,29}=67.58 ; \mathrm{P}<0.0001\right)$. As shown in Figure 2, SKF38393 significantly induced regular food intake at doses of 1.25 and $2.5 \mu \mathrm{g},(\mathrm{P}<0.001$, $\mathrm{P}<0.0001$, respectively) after $1 \mathrm{~h}$. Maximum stimulation of regular food intake was observed in the presence of 2.5 $\mu \mathrm{g}$ SKF38393. Figure 2 also revealed that food intake decreased significantly in the presence of $5 \mu \mathrm{g}$ SKF38393. We observed that this inhibitory effect rose from the SKF38393-induced immobility at higher doses.

\subsection{Time-course of SKF38393-induced food intake}

Figure 3 shows the standard food intake pattern over time following microinjection of SKF38393 into the VTA. Using 2-way ANOVA, we found that the stimulatory effect of SKF38393 $(2.5 \mu \mathrm{g})$ on feeding behavior remained up to 2 hours. In the SKF38393-treated rats, the Mean \pm SD magnitude of food intakes in the first and second hour post-injec- 


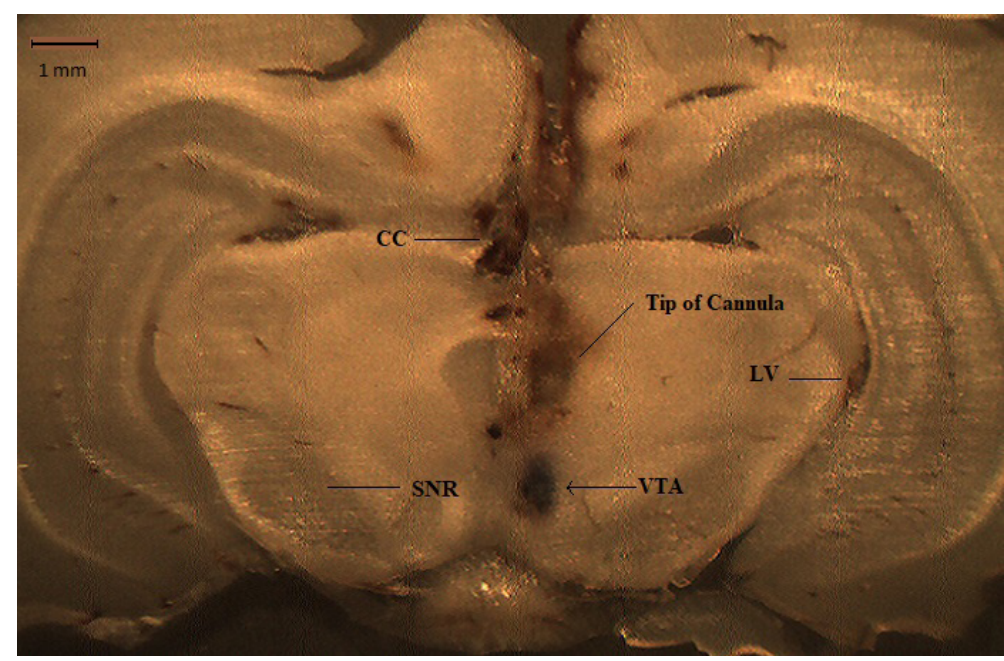

NEUR SCIENCE

Figure 1. Diagrams of coronal sections depicting actual injection sites and histological examination, and representative photomicrograph of the transverse section showing the intra-VTA injection

CC: Central Canal; LV: Lateral Ventricle; SNR: Substantia Nigra Reticular Part; VTA: Ventral Tegmental Area.

tion were $2.36 \pm 0.08$ and $1.3 \pm 0.08$ compared with $1.45 \pm 0.06$ and $0.5 \pm 0.06$ in the saline-treated group, respectively (treatment factor: $\mathrm{F}_{1,2}=241.2, \mathrm{P}<0.004$; time factor: $\mathrm{F}_{2,4}=179.4$, $\mathrm{P}<0.0001$; drug $\times$ time: $\mathrm{F}_{2,4}=31.7, \mathrm{P}<0.0037$ ). As shown in Figure 3, the food intake in SKF38393-treated rats was more than 2-fold higher than the saline-treated animals 2 $\mathrm{h}$ post-injection.

\subsection{Effects of VTA administrations of SKF38393 on locomotor activity}

To examine whether SKF38393 affects locomotor activity, we studied the effects of D1 receptor agonist SKF38393 on locomotor activity. Our results showed that the microinjection of $5 \mu \mathrm{g}$ of SKF38393 makes animal immovable, but a VTA microinjection of SKF38393 2.5 $\mu \mathrm{g}$ did not affect locomotor activity compared with the control group (Figure 4).

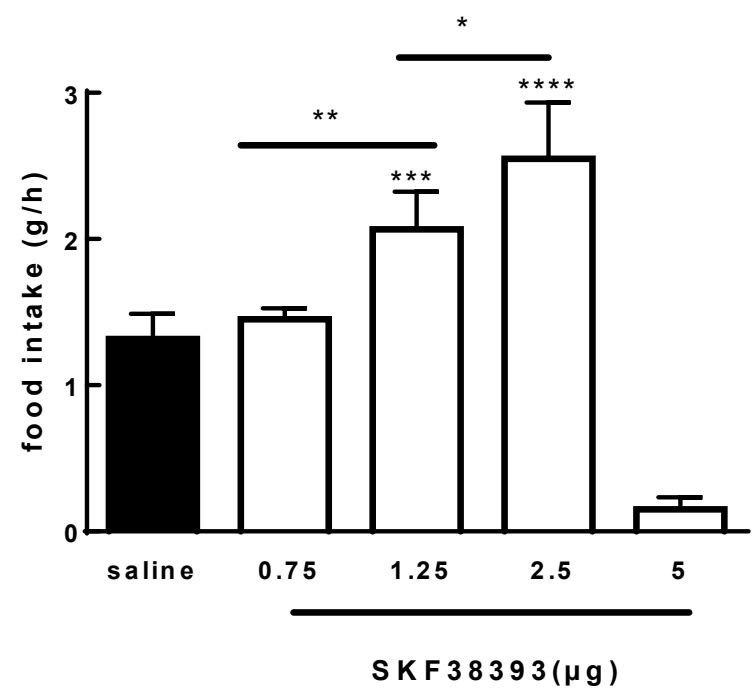

Figure 2. Stimulatory effects of VTA injections of SKF38393 on food intake

Dose-response effect of SKF38393 $(0.75,1.25,2.5$, and $5 \mu \mathrm{g} / 0.3 \mu \mathrm{L})$ and saline $(0.3 \mu \mathrm{L})$ on food intake were determined $1 \mathrm{~h}$ after injection. Data are presented as Mean \pm SEM ( $n=6$ per group).

${ }^{*} \mathrm{P}<0.05$; ${ }^{* *} \mathrm{P}<0.01$; ${ }^{* * *} \mathrm{P}<0.001$; and ${ }^{* * * *} \mathrm{P}<0.0001$ compared to the saline group. 


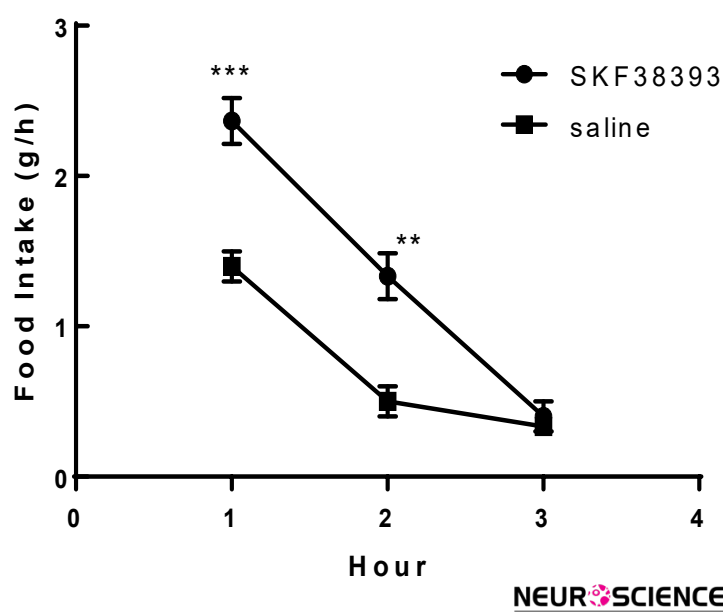

Figure 3. Characterization of the effects of SKF38393 (2.5 $\mu \mathrm{g} 0.3 \mu \mathrm{L}$ ) on food intake over a 3-h period Two-way ANOVA analyzes revealed that microinjection of SKF38393 (2.5 $\mu \mathrm{g})$ in VTA increases food intake more than 2-fold higher than the saline-treated animals 2-h post-injection;

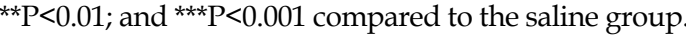

\section{Discussion}

The current experiments were conducted to determine the role of VTA dopamine D1 receptors in the regulation of consistent chow intake. In this study, we have shown that VTA-microinjected SKF38393, as a D1-like receptor agonist, increased food intake. Dopamine's role in feeding behavior has been studied by genetically removed tyrosine hydroxylase (Palmiter, 2007; Zhou \& Palmiter, 1995). These experimental animals survived only a few weeks after birth. These studies were unable to determine which dopaminergic pathways are involved and if the decreased food intake has an essential effect. Central dopaminergic pathways arising from the midbrain (substantia nigra and VTA) couple food intake to its rewarding properties, while the mediobasal hypothalamus (tuberoinfundibular neurons) links feeding to energy deficit (Schultz, 1997; Wise, 2004). For example, it has been reported that the VTA dopamine neurons, a key structure in the mesolimbic reward system, play pivotal roles in reinforcement, motivation, motor control, and learning (Ikemoto, 2007; Redgrave \& Gurney, 2006). Synaptic input and or output connections of VTA-dopamine neurons are important keys in feeding behavioral roles (Lammel et al., 2012). VTA dopamine neurons receive input from the ventral striatum, the lateral orbital cortex, the lateral hypothalamus (Wang et al., 2001), etc. In addition to the innervation of dopamine neurons by GABAergic (gamma-aminobutyric acid) interneurons, inhibitory GABA afferents of the nucleus

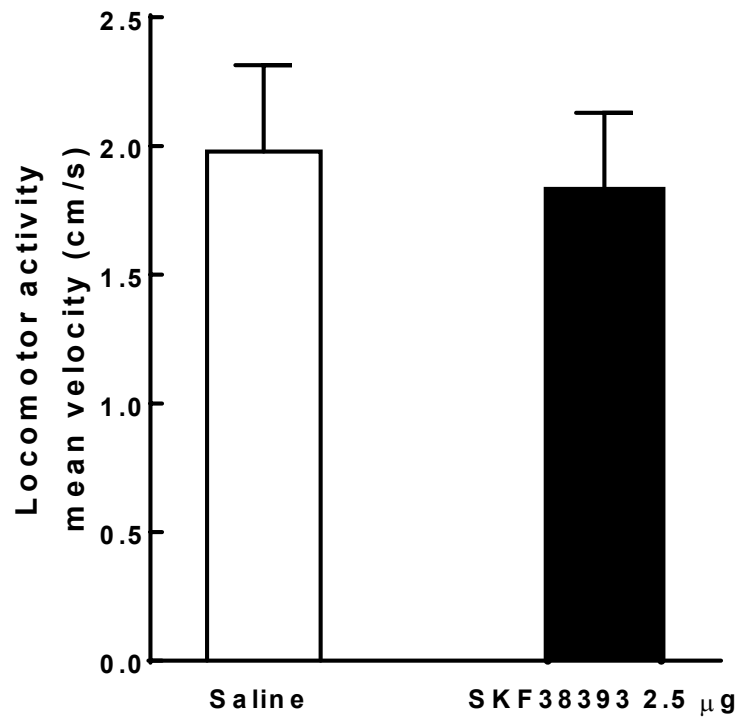

NEUR SCIENCE

Figure 4. Effects of VTA injections of SKF38393 on locomotor activity over a $1 \mathrm{~h}$ period

SKF38393 $(2.5 \mu \mathrm{g})$ did not affect locomotor activity compared to the control group. Data are presented as Mean \pm SEM ( $\mathrm{n}=$ 6 per group).

accumbens and ventral pallidum project to the VTA (Kalivas, 1993; Yim \& Mogenson, 1980).

The VTA dopaminergic cells also project to brain sites, including the NAcC, NAc shell (Fallon \& Moore, 1978), the central nucleus of the amygdala (Mogenson \& $\mathrm{Wu}$, 1982), the hippocampus (Scatton et al., 1980), and the prefrontal cortex (Berger et al., 1976). Moreover, inputs from two brainstem nuclei, laterodorsal tegmental nucleus (LDTg) and Pedunculopontine Tegmental nucleus (PPTg) regulate dopamine neuron activity (Oakman, Faris, Kerr, Cozzari, \& Hartman, 1995; Omelchenko \& Sesack, 2005). Projections of LDTg and PPTg to the VTA contain glutamatergic, cholinergic, and GABAergic afferents that synapse onto dopaminergic cell bodies (Geisler, Derst, Veh, \& Zahm, 2007; Omelchenko \& Sesack, 2005). To date, at least 5 dopamine receptors have been classified into two families of D1-like (D1 and D5) and D2-like (D2, D3, and D4) receptors (Sunahara et al., 1991; Van Tol et al., 1991). Our previous studies and others have shown that modulation of the hypothalamic D1 and D2 dopamine receptor activity could modulate food intake (Mirmohammadsadeghi, Brojeni, Haghparast, \& Eliassi, 2018; Salimi, Eliassi, \& Haghparast, 2015). Although D1 and D2 dopamine receptors also exist in the VTA and participate in behavioral rewards (Galaj, Manuszak, Arastehmanesh, \& Ranaldi, 2014; White \& Wang, 1984), its modulatory action on standard chow behavior has remained unexplored. 
In the current study, we showed that intra-VTA injections of SKF3833 increased standard food intake in a dose-dependent manner. Both dopamine D1 and D5 receptors are activated by SKF38393 as a selective dopamine D1-like receptor agonist (Andersen \& Jansen, 1990).

The VTA dopamine D1 receptors are located on the descending projections of glutamate and GABA terminals (Lu, Churchill, \& Kalivas, 1997). These dopamine D1 receptor's activation facilitates VTA's GABA (Giorgetti, Hotsenpiller, Froestl, \& Wolf, 2002) and glutamate (Nakanishi, 1992) release, which modulates dopamine release through inhibition or excitation of the VTA dopamine cells, respectively (Cameron \& Williams, 1993; Klitenick et al., 1992). Therefore, there is a possibility that the VTA microinjection of SKF38393, by stimulation of dopamine D1 receptors on glutamate afferents, induces glutamate release and increases dopamine neural activity and standard chow intake. In line with our study, Galaj et al. (2014) demonstrated that VTA dopamine D1 receptor stimulation plays a role in the rewarding effects of cocaine (Galaj et al., 2014). Furthermore, a decreased food reward was observed in animal treated with the VTA-microinjected dopamine D1 receptor antagonist (Sharf, Lee, \& Ranaldi, 2005). Notably, SKF38393 also activates dopamine D5 receptors, a selective agonist activating dopamine D1 and D5 receptors separately does not yet exist. VTA dopamine neurons express somatic D5 receptors instead of dopamine D1 receptors (Ciliax et al., 2000; Khan et al., 2000).

We cannot rule out that intra-VTA microinjection of SKF38393 may increase regular food intake through stimulation of dopamine somatic D5 receptors. In addition, a dense innervation of serotonergic terminals to the VTA, NAc, and PFC was observed (Halliday \& Törk, 1989). Indeed, serotonin affects cocaine's action through its 5-HT2A and 5-HT2C receptors, which co-exist in the VTA, the NAc, and the PFC (Pompeiano, Palacios, \& Mengod, 1994). It has been reported that serotonergic receptors, instead of dopamine D1 receptors, may mediate certain behavioral effects of SKF38393. For example, Zarrindast et al. suggested that the inhibitory action of SKF38393 in feeding behavior may be mediated through serotonergic mechanisms (Zarrindast, Owji, \& Hosseini-Nia, 1991). Furthermore, it has been reported that the inhibitory effect of SKF38393 on food intake was reversed by the 5-HT2C antagonist metergoline (Schreiber et al., 1995). Thus, the VTA SKF3833-induced standard chow may be mediated via serotonergic receptors. Further studies are needed to resolve the interaction between the two VTA neurotransmitters, dopamine and or serotonin, on regular feeding behavior. It is well known that dopamine D1 receptors participate in controlling movement (Carlsson, 1993; Starr \& Starr, 1987). Interestingly, our results showed that VTA administration of SKF38393 did not affect locomotor activity in the same dose range that was effective on regular food intake.

For the first time, the current study found that ventral tegmental areas not only affect food reward but also participate in regulatory mechanisms of regular feeding, at least in part, through dopamine fibers. This pathway stimulates regular food intake, probably through D1-like receptors and or serotonergic receptors. Besides, our results demonstrated that intra-VTA administration of SKF38393 increased food intake without any effect on locomotor activities. Based on the present findings, it is important to understand the VTA mechanisms involved in regular food intake and its possible use in treating eating disorders.

\section{Ethical Considerations}

\section{Compliance with ethical guidelines}

This study was approved by the Ethics Committee of Shahid Beheshti University of Medical Sciences (Code: IR.SBMU.MSP.REC.1397.155).

\section{Funding}

This work was supported with a grant from the Neurophysiology Research Center of Shahid Beheshti University of Medical Sciences.

\section{Authors' contributions}

Conceptualization: Afsaneh Eliassi; Data collection: Farzaneh saebi Rad; Data analysis: Farzaneh Saebi Rad; Writing - original draft: Afsaneh Eliassi, Farzaneh saebi Rad; Writing - review \& editing: Afsaneh Eliassi and Abbas Haghparast; Investigation: Faculty of Medicine, and Neurophysiology Research Center, Shahid Beheshti University of Medical Sciences; Supervision: Afsaneh Eliassi; Founding acquisition: Neurophysiology Research Center, Shahid Beheshti University of Medical Sciences.

\section{Conflict of interest}

The authors declared no conflict of interest.

\section{References}

Andersen, P. H., \& Jansen, J. A. (1990). Dopamine receptor agonists: Selectivity and dopamine D1 receptor efficacy. European 
Journal of Pharmacology: Molecular Pharmacology, 188(6), 335-347. [DOI:10.1016/0922-4106(90)90194-3]

Berger, B., Thierry, A. M., Tassin, J. P., \& Moyne, M. A. (1976). Dopaminergic innervation of the rat prefrontal cortex: A fluorescence histochemical study. Brain Research, 106(1), 133-45. [DOI:10.1016/0006-8993(76)90078-0]

Cameron, D. L., \& Williams, J. T. (1993). Dopamine D1 receptors facilitate transmitter release. Nature, 366(6453), 344-7. [DOI:10.1038/366344a0] [PMID]

Carlsson, A. (1993). On the neuronal circuitries and neurotransmitters involved in the control of locomotor activity. Journal of Neural Transmission. Supplementum, 40, 1-12. [PMID]

Ciliax, B. J., Nash, N.,Heilman, C., Sunahara, R., Hartney, A., \& Tiberi, M., et al. (2000). Dopamine D5 receptor immunolocalization in rat and monkey brain. Synapse, 37(2), 125-45. [DOI:10.1002/10982396(200008)37:2<125::AID-SYN7>3.0.CO;2-7] [PMID]

Corrigall, W. A., Franklin, K. B., Coen, K. M., \& Clarke, P. B. (1992) The mesolimbic dopaminergic system is implicated in the reinforcing effects of nicotine. Psychopharmacology, 107(2-3), 285-9. [DOI:10.1007/BF02245149] [PMID]

Datla, K., Ahier, R., Young, A., Gray, J., \& Joseph, M. (2002). Conditioned appetitive stimulus increases extracellular dopamine in the nucleus accumbens of the rat. European Journal of Neuroscience, 16(10), 1987-93. [DOI:10.1046/j.1460-9568.2002.02249.x] [PMID]

Fallon, J. H., \& Moore, R. Y. (1978). Catecholamine innervation of the basal forebrain IV. Topography of the dopamine projection to the basal forebrain and neostriatum. Journal of Comparative Neurology, 180(3), 545-79. [DOI:10.1002/cne.901800310] [PMID]

Galaj, E., Manuszak, M., Arastehmanesh, D., \& Ranaldi, R. (2014) Microinjections of a dopamine D1 receptor antagonist into the ventral tegmental area block the expression of cocaine conditioned place preference in rats. Behavioural Brain Research, 272, 27985. [DOI:10.1016/j.bbr.2014.07.008] [PMID]

Gao, Q., \& Horvath, T. L. (2007). Neurobiology of feeding and energy expenditure. Annual Review of Neuroscience, 30, 367-98. [DOI:10.1146/annurev.neuro.30.051606.094324] [PMID]

Geisler, S., Derst, C., Veh, R. W., \& Zahm, D. S. (2007). Glutamatergic afferents of the ventral tegmental area in the rat. Journal of Neuroscience, 27(21), 5730-43. [DOI:10.1523/JNEUROSCI.0012-07.2007] [PMID] [PMCID]

Giorgetti, M., Hotsenpiller, G., Froestl, W., \& Wolf, M. (2002). In vivo modulation of ventral tegmental area dopamine and glutamate efflux by local GABAB receptors is altered after repeated amphetamine treatment. Neuroscience, 109(3), 585-95. [DOI:10.1016/ S0306-4522(01)00510-3]

Halliday, G. M., \& Törk, I. (1989). Serotonin-like immunoreactive cells and fibres in the rat ventromedial mesencephalic tegmentum. Brain Research Bulletin, 22(4), 725-35. [DOI:10.1016/03619230(89)90092-0]

Ikemoto, S. (2007). Dopamine reward circuitry: Two projection systems from the ventral midbrain to the nucleus accumbensolfactory tubercle complex. Brain Research Reviews, 56(1), 27-78. [DOI:10.1016/j.brainresrev.2007.05.004] [PMID] [PMCID]

Kalivas, P. W. (1993). Neurotransmitter regulation of dopamine neurons in the ventral tegmental area. Brain Research Reviews, 18(1), 75-113. [DOI:10.1016/0165-0173(93)90008-N]
Kalivas, P. W., \& Duffy, P. (1995). D1 receptors modulate glutamate transmission in the ventral tegmental area. Journal of Neuroscience, 15(7), 5379-88. [DOI:10.1523/JNEUROSCI.15-07-05379.1995] [PMID] [PMCID]

Khan, Z., Gutierrez, A., Martın, R., Penafiel, A., Rivera, A., \& De La Calle, A. (2000). Dopamine D5 receptors of rat and human brain. Neuroscience, 100(4), 689-99. [DOI:10.1016/S0306-4522(00)00274-8]

Klitenick, M. A., DeWitte, P., \& Kalivas, P. W. (1992). Regulation of somatodendritic dopamine release in the ventral tegmental area by opioids and GABA: An in vivo microdialysis study. Journal of Neuroscience, 12(7), 2623-32. [DOI:10.1523/JNEUROSCI.12-07-02623.1992] [PMID] [PMCID]

Lammel, S., Lim, B. K., Ran, C., Huang, K. W., Betley, M. J., \& Tye, K. M., et al. (2012). Input-specific control of reward and aversion in the ventral tegmental area. Nature, 491(7423), 212-7. [DOI:10.1038/nature11527] [PMID] [PMCID]

Ljungberg, T., Apicella, P., \& Schultz, W. (1992). Responses of monkey dopamine neurons during learning of behavioral reactions. Journal of Neurophysiology, 67(1), 145-63. [DOI:10.1152/ jn.1992.67.1.145] [PMID]

Lu, X. Y., Churchill, L., \& Kalivas, P. W. (1997). Expression of D1 receptor mRNA in projections from the forebrain to the ventral tegmental area. Synapse, 25(2), 205-14. [DOI:10.1002/(SICI)10982396(199702)25:2<205::AID-SYN11>3.0.CO;2-X] [PMID]

Mirenowicz, J., \& Schultz, W. (1994). Importance of unpredictability for reward responses in primate dopamine neurons. Journal of Neurophysiology, 72(2), 1024-7. [DOI:10.1152/jn.1994.72.2.1024] [PMID]

Mirmohammadsadeghi, Z., Shareghi Brojeni, M., Haghparast, A., \& Eliassi, A. (2018). Role of paraventricular hypothalamic dopaminergic D1 receptors in food intake regulation of food-deprived rats. European Journal of Pharmacology, 818, 43-9. [DOI:10.1016/j. ejphar.2017.10.028] [PMID]

Mogenson, G. J., \& Wu, M. (1982). Electrophysiological and behavioral evidence of interaction of dopaminergic and gustatory afferents in the amygdala. Brain Research Bulletin, 8(6), 685-91. [DOI:10.1016/0361-9230(82)90096-X]

Morales, M., \& Root, D. H. (2014). Glutamate neurons within the midbrain dopamine regions. Neuroscience, 282, 60-8. [DOI:10.1016/j. neuroscience.2014.05.032] [PMID] [PMCID]

Nakanishi, S. (1992). Molecular diversity of glutamate receptors and implications for brain function. Science, 258(5082), 597-603. [DOI:10.1126/science.1329206] [PMID]

Oakman, S. A., Faris, P. L., Kerr, P. E., Cozzari, C., \& Hartman, B K. (1995). Distribution of pontomesencephalic cholinergic neurons projecting to substantia nigra differs significantly from those projecting to ventral tegmental area. Journal of Neuroscience, 15(9), 5859-69. [DOI:10.1523/JNEUROSCI.15-09-05859.1995] [PMID] [PMCID]

Omelchenko, N., \& Sesack, S. R. (2005). Laterodorsal tegmental projections to identified cell populations in the rat ventral tegmental area. Journal of Comparative Neurology, 483(2), 217-35. [DOI:10.1002/cne.20417] [PMID]

Palmiter, R. D. (2007). Is dopamine a physiologically relevant mediator of feeding behavior? Trends in Neurosciences, 30(8), 375-81. [DOI:10.1016/j.tins.2007.06.004] [PMID] 
Papp, M., \& Bal, A. (1986). Motivational versus motor impairment after haloperidol injection or 6-OHDA lesions in the ventral tegmental area or substantia nigra in rats. Physiology \& Behavior, 38(6), 773-9. [DOI:10.1016/0031-9384(86)90042-9]

Paxinos, G., \& Watson, C. (2006). The rat brain in stereotaxic coordinates, $6^{\text {th }}$ edition. Elsevier.

Pioli, E., Meissner, W., Sohr, R., Gross, C., Bezard, E., \& Bioulac, B. (2008). Differential behavioral effects of partial bilateral lesions of ventral tegmental area or substantia nigra pars compacta in rats. Neuroscience, 153(4), 1213-24. [DOI:10.1016/j.neuroscience.2008.01.084] [PMID]

Pompeiano, M., Palacios, J. M., \& Mengod, G. (1994). Distribution of the serotonin 5-HT2 receptor family mRNAs: Comparison between 5-HT2A and 5-HT2C receptors. Molecular Brain Research, 23(1-2), 163-78. [DOI:10.1016/0169-328X(94)90223-2]

Redgrave, P., \& Gurney, K. (2006). The short-latency dopamine signal: A role in discovering novel actions? Nature Reviews Neuroscience, 7(12), 967-75. [DOI:10.1038/nrn2022] [PMID]

Root, D. H., Mejias-Aponte, C. A., Zhang, Sh., Wang, H. L., Hoffman, A. F., \& Lupica, C. R., et al. (2014). Single rodent mesohabenular axons release glutamate and GABA. Nature Neuroscience, 17(11), 1543-51. [DOI:10.1038/nn.3823] [PMID] [PMCID]

Salimi, M., Eliassi, A., \& Haghparast, A. (2015). [Intra-paraventricular nucleus microinjection of D2 receptors antagonist, sulpiride, reduces food intake in 24 hours food-deprived rats (Persian)]. Iranian Journal of Physiology and Pharmacology, 1(3), 193-200. http:/ / ijpp.phypha.ir/article-1-271-en.html

Scatton, B., Simon, H., Le Moal, M., \& Bischoff, S. (1980). Origin of dopaminergic innervation of the rat hippocampal formation. Neuroscience Letters, 18(2), 125-31. [DOI:10.1016/0304-3940(80)90314-6]

Schreiber, R., Brocco, M., Audinot, V., Gobert, A., Veiga, S., \& Millan, M. J. (1995). (1-(2,5-dimethoxy-4 iodophenyl)-2-aminopropane)induced head-twitches in the rat are mediated by 5-hydroxytryptamine (5-HT) 2A receptors: modulation by novel 5-HT2A/2C antagonists, D1 antagonists and 5-HT1A agonists. Journal of Pharmacology and Experimental Therapeutics, 273(1), 101-12. [PMID]

Schultz, W. (1997). Dopamine neurons and their role in reward mechanisms. Current Opinion in Neurobiology, 7(2), 191-7. [DOI:10.1016/S0959-4388(97)80007-4]

Sharf, R., Lee, D. Y., \& Ranaldi, R. (2005). Microinjections of SCH 23390 in the ventral tegmental area reduce operant responding under a progressive ratio schedule of food reinforcement in rats. Brain Research, 1033(2), 179-85. [DOI:10.1016/j.brainres.2004.11.041] [PMID]

Smith, Y., Charara, A., \& Parent, A. (1996). Synaptic innervation of midbrain dopaminergic neurons by glutamate-enriched terminals in the squirrel monkey. Journal of Comparative Neurolooy, 364(2), 231 53. [DOI:10.1002/(SICI)1096-9861(19960108)364:2<231::AIDCNE4>3.0.CO;2-6] [PMID]

Starr, B., \& Starr, M. (1987). Behavioural interactions involving D1 and D2 dopamine receptors in non-habituated mice. Neuropharmacology, 26(6), 613-9. [DOI:10.1016/0028-3908(87)90155-9]

Stricker, E. M., \& Zigmond, M. J. (1984). Brain catecholamines and the central control of food intake. International Journal of Obesity, 8(1), 39-50. [PMID]

Sunahara, R. K., Guan, H. C., O’Dowd, B. F., Seeman, P., Laurier, L. G., \& Ng, G., et al. (1991). Cloning of the gene for a human do- pamine D5 receptor with higher affinity for dopamine than D1 Nature, 350(6319), 614-9. [DOI:10.1038/350614a0] [PMID]

Van Tol, H. H., Bunzow, J. R., Guan, H. C., Sunahara, R. K., Seeman P., \& Niznik, H. B., et al. (1991). Cloning of the gene for a human dopamine D4 receptor with high affinity for the antipsychotic clozapine. Nature, 350(6319), 610-4. [DOI:10.1038/350610a0] [PMID]

Wang, G. J., Volkow, N. D., Logan, J., Pappas, N. R., Wong, C. T. \& Zhu, W., et al. (2001). Brain dopamine and obesity. The Lancet, 357(9253), 354-7. [DOI:10.1016/S0140-6736(00)03643-6]

White, F. J., \& Wang, R. Y. (1984). Pharmacological characterization of dopamine autoreceptors in the rat ventral tegmental area: Microiontophoretic studies. Journal of Pharmacology and Experimental Therapeutics, 231(2), 275-80. [PMID]

Wise, R. A. (1978). Catecholamine theories of reward: A critica review. Brain Research, 152(2), 215-47. [DOI:10.1016/00068993(78)90253-6]

Wise, R. A. (2004). Dopamine, learning and motivation. Nature Reviews Neuroscience, 5(6), 483-94. [DOI:10.1038/nrn1406] [PMID]

Wise, R. A. (2006). Role of brain dopamine in food reward and reinforcement. Philosophical Transactions of the Royal Society B: Biological Sciences, 361(1471), 1149-58. [DOI:10.1098/rstb.2006.1854] [PMID] [PMCID]

Wisman, L. A., Sahin, G., Maingay, M., Leanza, G., \& Kirik, D. (2008) Functional convergence of dopaminergic and cholinergic input is critical for hippocampus-dependent working memory. Journal of Neuroscience, 28(31), 7797-807. [DOI:10.1523/JNEUROSCI.1885-08.2008] [PMID] [PMCID]

Yim, C. Y., \& Mogenson, G. J. (1980). Effect of picrotoxin and nipecotic acid on inhibitory response of dopaminergic neurons in the ventral tegmental area to stimulation of the nucleus accumbens. Brain Research, 199(2), 466-72. [DOI:10.1016/0006-8993(80)90705-2]

Zarrindast, M., Owji, A., \& Hosseini-Nia, T. (1991). Evaluation of dopamine receptor involvement in rat feeding behaviour. General Pharmacology, 22(6), 1011-6. [DOI:10.1016/0306-3623(91)90570-V]

Zhou, Q. Y., \& Palmiter, R. D. (1995). Dopamine-deficient mice are severely hypoactive, adipsic, and aphagic. Cell, 83(7), 1197-209. [DOI:10.1016/0092-8674(95)90145-0] 